Revista de Estudios Histórico-Jurídicos

[Sección historia de los derechos patrios de América]

XXXVII (Valparaíso, Chile, 2015)

[pp. 211 - 231]

\title{
La Real Biblioteca Pública de Santa fe de Bogotá y SUS APORTES A LA CULTURA JURÍDICA EN IBEROAMÉRICA: LA obra DEL IlUSTRAdo MANUEl DEl SOCORRO RodríGUEZ*
}

[The Royal Public Library of Santa Fe de Bogota and its Contributions to the Legal Culture in Ibero-America: the Work of Manuel del Socorro Rodriguez, an Intellectual of the Enlightment]

\author{
Mónica Patricia Fortich Navarro** \\ Universidad Libre, Bogotá, Colombia
}

\section{RESUMEN}

El artículo presenta una síntesis del perfil biográfico de Manuel del Socorro Rodríguez y sus aportes como bibliotecario de la Real Biblioteca de Santa Fe, en la divulgación de textos y discursos sobre el derecho, para la formación de la cultura jurídica republicana en el marco del proceso de independencia, a partir de la oposición entre regalismo y americanismo.

Palabras Clave

Real Biblioteca Pública de Santa Fe Manuel del Socorro Rodríguez - Bibliotecas indianas.

\section{Abstract}

This article is a summary of Manuel del Socorro Rodríguez' bibliographic profile and his contributions, as a librarian of the Royal Library of Santafé, to make legal texts and discourses known in order to form the Republican legal culture within the context of the Independence process, based on the opposition between the monarchists and the Americanists.

\section{KeYWORDS}

Royal Public Library of Santa Fe Manuel del Socorro Rodríguez - Libraries of the Indies.

RECIBIDO el 24 de julio y ACEPTADO el 10 de agosto de 2015

* Artículo resultado en el marco del proyecto de investigación socio-jurídica titulada "Textos y discursos en la formación del derecho colombiano 1777-1820. La Real Biblioteca de Santa Fe y sus aportes a la cultura jurídica”, Grupo de investigación en derecho, sociedad y estudios internacionales, Centro de Investigaciones Socio-Jurídicas, Facultad de Derecho de la Universidad Libre, 2014.

** Magíster en literatura hispanoamericana, Seminario Andrés Bello, Instituto Caro y Cuervo. Doctora en sociología jurídica e instituciones políticas por la Universidad Externado de Colombia. Candidata al doctorado en derecho y ciencias sociales por la Facultad de Derecho de la Universidad Nacional de Educación a Distancia, Madrid, España. Docente e investigadora del Centro de Investigaciones Socio-Jurídicas de la Facultad de Derecho de la Universidad Libre, Bogotá. Correos electrónicos: monicafortichnavarro@hotmail.com y monica.fortich@ unilibre.edu.co 


\section{INTRODUCCIÓN}

La figura de Manuel de Socorro Rodríguez de la Victoria es un punto de referencia obligado de la historia sobre el periodismo y la literatura neogranadina y su nombre está ligado al proceso de formación de la Real Biblioteca Pública. Su obra es uno de los principales hitos ilustrados en la construcción de la identidad republicana de Colombia, en la consolidación de un pensamiento propio a partir del cual fue posible inaugurar esa tradición jurídico-política republicana en Colombia.

El presente artículo es parte del informe final de la investigación cuyo proyecto denominamos "La Real Biblioteca de Santa Fe y sus aportes a la cultura jurídica colombiana (1777-1810). Textos y discursos en la formación del derecho colombiano (1777-1830)", que propone un recorrido por el proceso de construcción y consolidación de la tradición jurídica colombiana desde la perspectiva de los procesos de creación y circulación de las ideas contenidas en los libros jurídicopolíticos de la época, con los cuales se agitaban los procesos revolucionarios de cara a la independencia y el establecimiento de un nuevo derecho republicano en ruptura con la tradición colonial. Continúa con los ejercicios para la consolidación de una metodología de análisis denominada cultura del libro y que ha permitido documentar el corpus y canon de textos y discursos contenidos en libros jurídicos con los que se formaban los abogados neogranadinos y con los que más tarde se consolidaría la tradición jurídica republicana ${ }^{1}$.

En ese orden de ideas la pregunta que representa el problema general de investigación es la siguiente: ¿Cuáles son los textos y los discursos contenidos en los libros y la bibliotecas del Nuevo Reino de Granada que fueron esenciales en la formación del derecho republicano en el periodo preindependentista y el establecimiento de la república (1777-1830)? Y como consecuencia de ese ejercicio por etapas la primera parte de la investigación se centró en la pregunta: ¿Cuáles son los textos y discursos presentes en los libros de la Real Biblioteca de Santa Fe y su influencia en la formación de la tradición jurídica en el periodo preindependentista (1777-1810)? Es decir desde la apertura de la Real Biblioteca y los sucesos del 20 de julio de 1810.

En el presente texto reafirmamos el perfil del bibliotecario Manuel del Socorro Rodríguez de la Victoria como una pieza esencial en la formación del pensamiento ilustrado de la Nueva Granada, por el papel que él mismo y la Real Biblioteca Pública de Santa Fe, jugaron en la construcción de una conciencia sobre un pensamiento propio en el virreinato de Nueva Granada, y más allá de sus fronteras, una identidad como nación, un rol como ciudadano y una respuesta a las voces que veían con desdén la consolidación de una lectura del mundo en clave americana.

Desde su oficio como director de la Real Biblioteca de Santa Fe y el proceso de promoción de los valores y la cultura ilustrada que llegaban de ultramar, la figura del bibliotecario, del periodista y el literato se refunden con la del divulga-

${ }^{1}$ ForTich, Mónica, Togados y letrados, libros, lecturas y bibliotecas en la formación de los abogados neogranadinos, 1739-177 (Bogotá, 2011). 
dor de las ideas enciclopédicas que, de manera deliberada o indirecta, gestaron el proceso independentista en el Nuevo Reino de Granada, y pieza esencial para la organización de la naciente República, con el impacto que ello género en el resto de colonias españolas en el nuevo mundo.

Sin embargo, esta figura es paradójica, porque su vida y su obra pueden ofrecer una lectura compleja sobre las reales influencias de los valores ilustrados que se alimentaron en las tertulias y en los procesos de divulgación que se desarrollaron de la Real Biblioteca de Santa Fe. La biografía de Manuel del Socorro es la síntesis de un hombre de su tiempo que tuvo necesidad de plegarse obedientemente a las reglas del sistema de gobierno monárquico y expresar el respeto por las figuras centrales de la corona española, y luego del proceso de independencia su fervor republicano, reconfigurando dos posturas que se enfrentaban en la época: los valores del regalismo que predican la adhesión y obediencia por la Corona y el pensamiento americanista que propugnaba por la independencia de las colonias desde la consolidación de un pensamiento propio.

\section{El perfil humano de Manuel del Socorro Rodríguez de la Victoria.}

Desde la literatura y de la historia se han estudiado los procesos que determinan la formación de los textos y discursos con los que se construyen los colectivos. Para nuestro estudio es esencial señalar una biblioteca y un bibliotecario como elementos articuladores del flujo de creación y circulación discursiva en la sociedad neogranadina. Abordar la cuestión biográfica de Rodríguez, supone además de presentar su perfil humano, destacar cómo su trabajo ejerció una influencia en la conciencia de los neogranadinos, y así mismo en las ideas que llevaron a conquistar la independencia colombiana desde dos perspectivas que se presentan como antagónicas: la regalista y la americanista.

Partimos del origen humilde del bibliotecario, como el lugar común de sus biógrafos Torre Revello, Otero Muñoz y Cacua Prada, quienes ubican su nacimiento hacia el lunes tres de abril de 1758, como el único varón del matrimonio Rodríguez de la Victoria. Su padre Manuel Baltasar Rodríguez, era maestro de primeras letras y ejercía también el arte de la escultura supliendo los gastos que se generaban en la familia; mientras que su esposa María Antonia de la Victoria era una modesta pero virtuosa ama de casa.

Su origen humilde y la muerte de su padre a los 8 años de edad marcaron el comienzo de una vida de sacrificios y vejaciones, y el compromiso de velar por su madre y sus dos hermanas huérfanas. Desde la muerte de su padre asumió la labor de formación de los menesterosos que acudían a la escuela de la iglesia de Bayamo.

Según lo refiere un relato biográfico de la época, Manuel del Socorro era un profundo cristiano, no solo en su rol de monaguillo sino en el de maestro que expresó siempre su piedad como buen católico. Igualmente, cultivó las artes plásticas sin tutores ni maestros, al tiempo que daba muestra de su amor por la lectura y su pasión por los libros, rasgos que estaban acompañados por un carácter de pedagogo y autodidáctica: "Durante cuatro años se mantuvo al frente del centro educacional, hasta que se vio obligado a hacer abandono del mismo para consagrarse a la talla, pintura y dibujo. Sin embargo, agregaba el Vicario Fontaine, su 
principal afición eran los libros, a cuya lectura y estudio dedicaba de noche, por cuanto las horas del día las consagraba a trabajar para el sustento de los suyos"2.

En ese mismo sentido el vicario Fontaine, citado por José Torre Revello advierte no tener un conocimiento y control sobre los libros y las lecturas de joven maestro, en una conducta que es perfectamente comprensible frente al control de creación y circulación de libros que ejercía el clero sobre los fieles: "sus estudios - exponía a continuación- como que han sido nocturnos y privados nadie puede dar razón individual de ellos; empero las obras que he visto, y que ha dado al público en esta Villa manifiestan que no son bulgares [sic]"3.

Desde 1780 cuando cumplía los 30 años, Manuel del Socorro inicia una larga secuencia de memoriales y oficios dirigidos a la Corona española con el propósito de obtener el apoyo económico para una pensión que le permitiera estabilidad a sus hermanas jóvenes y su anciana madre, para que él pudiera viajar a España a continuar con su proceso de instrucción y poder terminar sus obras literarias. En 1784 en carta dirigida el Rey expresa su ambición de una pensión para el sostenimiento de su familia y su viaje a España, en un tono que es muestra de su profundo respeto y devoción por el monarca, y señalan el camino del regalismo con el que sella su pacto de adhesión con la Corona: "No ocurro yo, señor, a V. M. como vasallo benemérito sino como vasallo infeliz, que conociendo podía ser algún día útil al Estado, según mi vocación naturalísima a la Literatura [...]. No el deseo de distinguirme sobre los otros es el que me ha quitado salud sobre los libros, porque acá, señor, [...] se le hace burla al que tiene la idea generosa de escribir alguna obra [...]. La causa de mi aplicación ha sido querer ser útil a mi nación [...]"4.

Alrededor del año 1788 Manuel del Socorro conoce a José de Ezpeleta Galdeano Di-Castillo y Prado, miembro de la Orden de San Juan, con quien establece una estrecha amistad en La Habana. Luego de aprobar los exámenes que le fueran practicados por el llamado "Tribunal de Examen" es trasladado de Bayamo a la capital cubana. Posteriormente, en 1789, Ezpeleta es promovido a Virrey y mediante oficio 89 del 17 de abril de 1789 eleva una solicitud pidiendo licencia para trasladarse junto con Manuel del Socorro a la ciudad Bogotá ${ }^{5}$ (Cacua Prada, 1966).

Se puede observar que la amistad con Ezpeleta, resultó muy benéfica para Manuel del Socorro, pues gracias a él es que llega a ser el director de la Biblioteca Real; en su viaje realizado por Manuel del Socorro Rodríguez de la Victoria, estuvo unos días en Cartagena, luego siguió por el Río Magdalena hasta Honda y de allí, llega finalmente a Bogotá el 18 de octubre de 1790.

Ahora bien, antes del nombramiento como nuevo director Francisco Antonio Moreno y Escandón, ilustrado y también amante de la lectura, logró conseguir para la época de 1790, una dotación de libros que habían sido expropiados a los jesuitas. Se abre entonces la primera Biblioteca Pública el 9 de enero de 1777 y se

\footnotetext{
${ }^{2}$ Torre, José, Ensayo de una biografía del bibliotecario y periodista Don Manuel del Socorro Rodríguez, en Revista Thesaurus [año III], 3 (1947) 1-3, p. 3.

${ }^{3}$ Torre, José. Ensayo, cit. (n. 3), p. 3.

${ }^{4}$ Citado por CACUA, Antonio, Don Manuel del Socorro Rodríguez. Itinerario documentado de su vida, actuaciones y escritos. Fundador del Periodismo colombiano (Bogotá, ICELAC, 1985), p. 20.

${ }^{5}$ Ibíd., p. 80.
} 
escogió como sede un salón que hacía parte del edificio donde funcionó el Colegio de San Bartolomé: "Siendo el Teniente General de la real armada y Caballero de San Juan, Don Miguel Guirior, virrey del Nuevo Reino de Granada, don Francisco Antonio, quien había actuado como juez ejecutor en la expulsión de los jesuitas, como "íntimo confidente del Virrey Messía de la Zerda en aquel reservadísimo negocio", consiguió que con los 4.182 libros dejados por los padres de la Compañía se organizara una Biblioteca pública, lo que se hizo, pero sin acuerdo del Rey"'.

La Real Biblioteca fue creada el 9 de enero de 1777, posee ediciones originales, incunables y algunas obras de la literatura neogranadina. El mismo Manuel regala numerosos libros de su biblioteca personal y escribe memoriales para sugerir soluciones ante la falta de títulos, el robo y el debido mantenimiento de la biblioteca ${ }^{7}$.

Sin embargo, sería hasta el año de 1788 cuando por orden Real de 16 de abril se aprueba la erección de la biblioteca pública del virreinato con el título de Real Biblioteca Pública de Santa Fe, por solicitud del arzobispo virrey Antonio Caballero y Góngora. La amistad de Manuel del Socorro con el Virrey Ezpeleta le habría permitido escoger el cargo de bibliotecario que estaba vacante desde la muerte del anterior bibliotecario Joaquín Esguerra, entre otros cargos públicos de importancia para el virreinato, hecho que igual expresa la vocación de estudio del Bayamés y le permitiría estar cerca de los libros y de su sueño de creación literaria. Sería hasta el 20 de octubre de 1790 cuando Manuel del Socorro se posesiona como nuevo director de la Real Biblioteca ${ }^{8}$.

Luego de su posesión Rodríguez desempeñó su cargo con acierto, con una dotación de 200 pesos anuales para el mantenimiento del espacio de la biblioteca, atento al cuidado y custodia de los libros. Unos meses más tarde la Biblioteca no solo prestaba labores de consulta sino de formación, en efecto funcionó como escuela gratuita en la que se dictaban una serie de materias, entre ellas se pueden mencionar: las lecciones de educación teológica- política, las lecciones de historia sagrada, eclesiástica y mitológica, el estudio de elocuencia y poesía en todos sus ramos y el estudio metódico de la lengua y ortografía castellana?.

Cabe destacar que mientras estuvo al frente de la Biblioteca Pública realizó una obra activa como bibliotecario y muchos jóvenes pudieron enriquecer su espíritu en virtud a la decidida vocación que sintió por los libros. Aunque adelantaba sus labores con empeño, su meta era España, porque tenía claro su deseo de cursar estudios en centros más adelantados del viejo mundo, por eso insistía sobre su traslado a la Corte para completar su formación, razón por la que en el epistolario del Bibliotecario abundan las peticiones negada, sobre su visita a España y la provisión de recursos para sostener a su familia primero, luego a la Biblioteca, y en el ocaso de su vida para él mismo. Sin embargo, en su trabajo en la Real Bi-

${ }^{6}$ Ibíd., p. 82.

${ }^{7}$ Garavito, Julián, Un vínculo cultural entre Cuba y Colombia: Manuel del Socorro Rodríguez [disponible en: http://mdc.ulpgc.es/cdm/ref/collection/tebeto/id/147,_pp. 235-239, visitado en mayo 15 de 2014].

${ }^{8}$ Otero, Gustavo, Don Manuel del Socorro Rodríguez: homenaje en el II centenario de su nacimiento (Bogotá, Biblioteca del Banco de la República, 1938), p. 9.

${ }^{9}$ Torre, José, Ensayo, cit. (n. 3), p. 13. 
blioteca rápidamente se puso al frente de la labor formadora de los neogranadinos, en especial en construcción de un nuevo canon sobre la literatura americana ${ }^{10}$.

En su misión formadora la fundación de periódicos y la actividad de la tertulia, serían piezas claves. Su imagen como fundador del periodismo en la capital del Virreinato de la Nueva Granada, se le debe la publicación de las primeras hojas periodísticas y a su amor por las letras. Aunque ello no hubiera sido posible sin el apoyo decidido de su amigo el virrey Ezpeleta, un ilustrado que siempre favorecía la cultura y las artes en general. Gracias a sus buenos oficios y a los constantes informes del virrey, Manuel del Socorro obtuvo algunas partidas, aumentos de sueldo, dinero, para seguir su labor y para la compra de algunos libros con destino a la Real Biblioteca.

En efecto, como podrá constatarse en su testamento y notas manuscritas que dejó en su archivo, así como en el inventario de los libros de la Real Biblioteca, fueron muchos los textos jurídicos de propiedad del bibliotecario que él dona a la misma, y que reflejan su interés por la comprensión de la realidad jurídica de entre España y sus colonias. De acuerdo con la transcripción de los textos donados se relacionan en su informe de 1 de junio de 1796, aparece la Historia natural del Conde de Buffon, entre otros títulos, y entre los textos jurídicos los siguientes:

España dividida por sus provincias

Concordantia utrisque [sic] juris civilis et canonicis

Institutionem juris civilis

Bullarium humanum

Heineccio: Elementa juris civilis

Antiguos Tratados de paces y alianzas entre algunos reyes de Aragón y diferentes príncipes infieles

Práctica judicial, eclesiástica y secular

Elementos de derecho público, por don Joseph de Olmeda

Derecho público de la Europa, por Joseph Antonio de Abreu

Juntas generales de la Real Sociedad Vascongada

Memorias de Jurisprudencia, de Mr. Omer Falcon ${ }^{11}$.

La labor del bibliotecario fue incansable, ya en sus publicaciones periódicas, como en su intercambio epistolar solicitando el apoyo económico de la Corona y luego de los criollos republicanos. En efecto, en su obra epistolar hay un rastro de descontento frente al manejo y provisión de cargos públicos ocupados por naturales americanos. Manuel del Socorro Rodríguez de la Victoria sembró inquietudes intelectuales en sus discípulos y amigos, que aunque tímida o indirectamente germinaron en la gesta de la independencia. Vivió lo suficiente como para ver que la independencia de la Nueva Granada se materializaba: "Rodríguez no volvió a

\footnotetext{
${ }^{10}$ SEDEÑo, Kevin, La “apología de los ingenios neogranadinos” y la constitución del canon de la literatura colombiana: Manuel del Socorro Rodríguez (1758-1819) (Bogotá, Universidad Nacional de Colombia- Fundación Universitaria del Área Andina, 2011).

${ }^{11}$ Hernández De Alba, Guillermo y Carrasquilla, Juan, Historia de la Biblioteca Nacional de Colombia, (Bogotá: Instituto Caro y Cuervo, 1977) pp. 63-68.
} 
percibir sueldos. Y se vio precisado a vivir casi de la caridad pública, contando solo con la comida que le suministraba la familia Álvarez Lozano y con los escasísimos recursos pecuniarios que se procuraba, vendiendo dibujos a pluma que hacía"12.

Manuel del Socorro muere en abril de 1819 sumido en la pobreza y el abandono de la Corona española a quien con tanto fervor defendió, y lejos el apoyo de los fondos públicos que la naciente república debía proveerle para continuar su obra de custodio de la Real Biblioteca. Su sepelio se hizo con ayuda de Victoriano Garzón y Justo Pastor Lozano quienes en agradecimiento por haberles facilitado el sitio en la Biblioteca para pintar uno de los bastidores en donde debía instalarse el "monumento" de los jueves Santos, estaban atentos a saludo diario. Son ellos quienes lo encuentran en su lecho de muerte. El deceso quedo registrado en el "Libro de defunciones de 1765 a 1836" en la iglesia de los Agustinos, el día 3 de junio de $1819^{13}$.

Como parte de este perfil biográfico es necesaria una breve semblanza de sus obras más importantes, por una parte la creación del Papel periódico de Santa Fe, y las demás publicaciones periódicas y por la otra la Tertulia Eutrapélica, ambas vehículos para el cultivo de las letras y la circulación de los valores ilustrados en dos dimensiones, en primera instancia en el marco del proyecto regalista y luego del americanismo que favoreció la causa independentista.

\section{El "Papel periódico de Santa Fe" y otros periódicos de la época.}

Luego de haber transcurrido 50 años de la llegada de la imprenta al Nuevo Reino de Granada (1737 a Cartagena y 1777 a Bogotá), y de los primeros intentos de creación de periódicos como el Aviso de Terremoto y la Gaceta de Santa $\mathrm{Fe}$ de Bogotá, la misión de formación de hombres cultos que se había propuesto Manuel del Socorro, se concreta en la edición de una publicación periódica con la que pretendía ilustrar a los santafereños sobre temas literarios, la formación del estilo y el buen gusto.

El primer ejemplar del Papel Periódico de la Ciudad de Santa Fe de Bogotá apareció el 9 de febrero de 1791, siendo el redactor del mismo Manuel del Socorro Rodríguez. El Papel Periódico se publicó hasta el número 265 (el día 6 de enero de 1797), seis años más tarde, lo que coincide con el regreso del virrey Ezpeleta a España. Una breve descripción del aspecto del periódico señala que: "[...] se imprimía en pequeños cuadernos de ocho o más páginas y formaba tomos del volumen de un libro común. Por su tamaño, por su periodicidad y sus asuntos era una publicación de tipo intermedio entre el cotidiano y la revista. Inspirábase en el modelo de las gacetas coetáneas, editadas en España, en Méjico y en Lima. La múltiple versación del fundador reflejábase en el copioso acervo de sus páginas, ya por designio de Rodríguez, ya por la varia procedencia de sus colaboraciones"14.

El periódico tuvo gran acogida entre los lectores quienes a menos de un mes de primer tiraje eran alrededor de 400 suscriptores, entre ellos el mismo virrey y

\footnotetext{
${ }^{12}$ Torre, José, Ensayo, cit. (n. 3), p.28

${ }^{13}$ Cacua, Antonio, Don Manuel del Socorro Rodríguez, cit. (n. 4), pp. 235-237.

${ }^{14}$ Otero, Gustavo, Don Manuel del Socorro Rodríguez, cit. (n. 8), p. 13.
} 
el arzobispo, varios funcionarios y autoridades civiles, eclesiásticas y militares, y colaboradores en la redacción entre los cuales se contaba con figuras como la de Francisco Antonio Zea, José Celestino Mutis, Antonio Nariño, Francisco Javier Matiz, Vicente Gil de Tejada, José María Gruesso, Francisco Antonio Rodríguez, y fray José María Valdés, entre otros. Muchas de las publicaciones de estos patriotas serían divulgadas y compartidas, bajo seudónimo, en la tertulia del bibliotecario: "Los personajes que alimentaban el Papel periódico con su colaboración y suscripciones, la mayor parte aficionados a las ciencias y letras, construían una sociedad patriótico-literaria bajo el nombre de Tertulia Eutrapélica, de la que fue órgano oficial el seminario de Rodríguez"15.

Más allá de su inicial interés literario, en este periódico se estudiaron temas como la geografía, la flora medicinal e industrial, la historia, el comercio y la organización del virreinato. Se divulgaron y rectificaron noticias y se informaba sobre los procesos revolucionarios en Europa, se comentaban libros extranjeros, se planeaban mejoras públicas, y se avanzaba en la formación de una conciencia civil de lo propio: "Por la variedad de los colaboradores, puede inferirse, también, la variedad de las materias tratadas. Lo que le daba cierta unidad era el carácter local de sus temas, aunque de vez en cuando transcribía noticias o disertaciones de libros y periódicos forasteros, sobre todo en el último año de su existencia, en que casi todo su material se reducía a copiar las atrasadísimas y poco verídicas nuevas que se insertaban en la Gaceta de Madrid sobre la revolución francesa, comentada siempre con vistas hacia los intereses de la Corona española en el Nuevo Reino, en artículos nada menos. Esa fue preocupación constante del fiel vasallo que, a pesar de su corto vuelo, presentía ya la tempestad emancipadora"16.

Por supuesto no faltaron los temas jurídicos como eje central de las ediciones. Vale destacar que a comienzo del segundo año hubo 3 ediciones completas del Papel periódico dedicadas a hacer una reflexión sobre derecho público. En efecto, en los números del 52 a 54, publicados los días viernes 10 de febrero, 17 y 24 de 1972, respectivamente, Manuel del Socorro anuncia una serie de varios números en los que de forma amena y pensando en la utilidad pública, se instruyera a los lectores con un "plan científico sobre todo género de materias" y en esta oportunidad le correspondió el turno a la publicación de un discurso denominado Disertación sobre la idea del Derecho público universal: leida en la Real Academia de Santa Bárbara de Madrid, por el D.D.N. en 23 de octubre de 1787. Un aspecto de la disertación anónima desarrollada en 27 subdivisiones, y contenida en 21 folios son los siguientes apartes relacionados con la naturaleza, concepto, divisiones y fin del derecho público: "6. Forzados los hombres a buscar en el socorro y ayuda de sus semejantes [...] se vieron entre ellos nacer infinidad de oficios y obligaciones que si no hubiera sido por aquellas, no se habrian conocido. La malicia de los que no cumplian o no dejaban cumplir a los demás estas obli- [folio 6] obligaciones, y por otra parte el deseo de asegurar aquellas sociedades o compañias contra los que defuera quisieran perturbarlas, son las dos fuentes de donde se han originado tantos convenios que son

\footnotetext{
${ }^{15}$ Ibíd., p. 14.

${ }^{16}$ Ibíd., p. 16.
} 
otros tantos establecimientos del derecho que llamamos público. 7. No sin razón se llamó asi generalmente por todos, después de la famosa división del Emperador Justiniano en sus Instituciones. En ellas como es bien sabido, y dividió aquel Emperador todo el derecho en público, y privado, incluyendo en el primer miembro todas cuantas disposiciones miran en general el bien común; y en el segundo las que tienen por objeto los intereses de los particulares. Esta obscura explicación que nos propone Justiniano la entenderemos mejor y comprenderemos todas sus diferencias comparando los dos miembros entre si'"17.

En estos apartes se cita los ejemplos de derechos que se pueden renunciar como el de compraventa mediante la cual los contratantes pueden ceder, donar o renunciar a su derecho en favor de un tercero, o el caso de los derechos públicos como las contribuciones o gravámenes de los que no es posible renunciar. Igualmente, señalaba en el texto que cada vez más había un mayor número de contratos entre los particulares, mientras que en el derecho público existen contratos entre pueblos y naciones, en los primeros la relación se daba entre personas físicas y la segunda entre personas "morales", esto último hecho curioso que contrasta con la evolución del concepto moderno de persona jurídica. Además de su tono didáctico y de la simpleza en la redacción, esta disertación constituye una pieza de valor central para destacar el esfuerzo que desde el periódico se hacía por tratar de instruir a los lectores, muchos de ellos sin la mínima formación en asuntos de derecho: "9. Estas son las principales diferencias que se notan entre el derecho público $y$ el privado, de las que casi no hizo mención Justiniano, y por las que venimos en conocimiento de la definición del primero. No es otra cosa que el derecho que resulta de unas convenciones o pactos sociales entre personas de igual o desigual autoridad en las Sociedades, por las que señalan los derechos y las obligaciones de los que mandan y obedecen, y cuyo principal objeto es la pública seguridad. Todos los autores aunque no se conforman en la explicación de esta idea, lo dividen y distinguen en dos miembros que conviene a saber: en derecho público universal, y derecho público particular. La misma división de intereses que tienen las Naciones para mirar por su seguridady aumentos, les han obligado a celebrar con las demás ciertos pactos y convenios, ya en los generales tratados de Paces, ya en varios tratados particulares. De todos ellos resultan los diversos oficios u obligaciones que se deben guardar de nación á nación, y cuyos establecimientos forman lo que llamamos derecho público universal [...]"18.

En otros apartes se documenta el objeto y fines de cada uno de los contratos públicos que se celebran de acuerdo a las diferentes materias como gobernar, legislar, "hacer justicia, distribuir las gracias, empleos y honores, deponer a los que no cumplen, formar el fisco, permitir que se formen las juntas o cuerpos politicos", hacer tratados de paz, comercio y navegación con extranjeros, fortificar las plazas, levantar o licenciar tropas, declarar la guerra o hacer la paz, en sintesis, este derecho público universal debia " mantener el buen orden y la pública tranquilidad del Estado"19.

\footnotetext{
${ }^{17}$ Rodríguez, Manuel del Socorro, Disertación sobre la idea del Derecho Público universal: leida en la Real Academia de Santa Bárbara de Madrid, por el D.D.N. en 23 de octubre de 1787 en Papel Periódico de Santa Fe, Bogotá, 10 de febrero, (1792), p. 6.

${ }^{18}$ Ibíd., p. 7.

${ }^{19}$ Ibíd., p. 8.
} 
En los siguientes números se ocuparía con mayor énfasis en señalar algunas características del derecho público universal en las naciones europeas y algunos textos esenciales que se encargaron del asunto como el de Juan Dumont en su obra Cuerpo universal diplomático del derecho de gentes, la obra Europa pacificada por la equidad de la reyna de Hungría cuyo autor no relaciona, la obra del Abate Mably Derecho público de Europa fundado en la fe de los tratados o en la obra De iure belli et pacis de Hugo Grocio, todas ellas, en su mayoría determinantes en la comprensión y desarrollo de un derecho internacional público como hoy lo conocemos, de un derecho diplomático particular que permitiera a las naciones recuperar la tranquilidad en medio de la guerra y la firma de tratados de paz duraderos. Todos esos discursos altamente sugestivos en momentos en los que en el viejo continente las confrontaciones entre los Estados eran una constantes de las relaciones internas e internacionales, el Papel Periódico abría a sus lectores una ruta de la discusión y de lecturas necesarias para ahondar en el fenómeno objeto de la anónima disertación ${ }^{20}$.

Finalmente, llama la atención del primer ejemplar de 1972 citado, que al final de la publicación que venimos comentando, se agrega una nota a los lectores en la que les recuerda renovar o cancelar la suscripción al periódico, con lo que creemos de la misma se hacía por anualidades, y que los lectores tuvieran la libertad de moverse del semanario en su mejor momento.

El éxito del Papel periódico de Santa Fe promovió la creación de nuevas publicaciones. Es así como el 17 de febrero de 1801 nace el Correo Curioso, erudito, económico y mercantil de la ciudad de Santa Fe de Bogotá, bajo la dirección de los criollos Jorge Tadeo Lozano y José Luis Azuola y Lozano, con el mismo plan del Papel Periódico. Este nuevo "periódico" estaba menos inclinado a la poesía y los versos como el que redactaba Manuel del Socorro Rodríguez.

Cabe resaltar además que Jorge Tadeo escribió sobre cuestiones económicas, razón por la que se le considera el primer economista que haya habido en Colombia, ya que al volver a su patria estaba imbuido en las nuevas ideas de la cultura borbónica y tocado de republicanismo por la Revolución Francesa. El Correo Curioso siguió apareciendo hasta el 29 de diciembre del mismo año de su fundación, en que se clausuró al completar 46 números. No tenía entonces sino 40 suscriptores y se vendían muy pocos ejemplares sueltos, porque tuvo que enfrentar constantes quejas y mala atmósfera que se hacía a la publicación.

Luego de la última edición del Papel Periódico, Manuel del Socorro se dedicó a poner en orden la Real Biblioteca, organizar el inventario de los textos y nutrir de nuevos títulos a la misma, con sus fondos personales. También se dedicó a su labor creativa, sus memorias personales, las tertulias y la labor formativa de los jóvenes neogranadinos. Años más tarde fundó, el 6 de diciembre de 1806, El Redactor Americano periódico del Nuevo Reino de Granada bajo los auspicios del virrey Amar y Borbón, periódico con un carácter semi-oficial fruto de la necesidad sentida contribuir con la "utilidad pública" informando a los santafereños: "Su redactor quiso grabar el frente de la publicación el símbolo de lo que pretendía que

${ }^{20}$ Ibíd., pp. 9-16. 
ella fuera, y así aparece allí una viñeta formada por una máscara con una pluma en la boca, a la cual circuía la frase Disfraz y pluma de todos, cuyo jeroglífico quería decir: "franquicia de escribir por este conducto cuanto fuere útil al público, según el plan del prospecto" 21 .

En el Redactor Americano, el bibliotecario fue consecuente con el conocimiento de los hechos que se gestaron en Francia, y los movimientos nacionalistas españoles que se formaron para expulsar a los franceses de su tierra, de la mano con la avanzada de tropas españolas contra los ingleses en el Río de la Plata. Las materias y asuntos del nuevo diario, según Manuel del Socorro no serían como las del Papel Periódico, de énfasis literario, sino un diario político para la difusión de temas americanos, en el que incluso quedaron proscritos los avisos comerciales o clasificados comunitarios. En su primer número se hicieron varias advertencias como el lugar de las noticias europeas que se editarían en un suplemento, que en caso de que el diario no prospera se devolvería el importe de la suscripción que las contribuciones y se advertía el carácter de los textos de manera no atentaran contra la urbanidad y el orden público: "Los buenos patriotas que quisieren contribuirle con sus luces, observaciones, noticias, orc. al mayor esplendor y perpetuidad de este útil establecimiento, podrán hacerlo dirigiendo sus producciones (sin franquicia de porte) por la Secretaría del Virreinato, con sobrescrito: Al Superior Gobierno para el Redactor Americano. Pero deben estar en l inteligencia, de que sólo se imprimirá lo que fuere digno de presentarse al Publico Ilustrado, católico y de buena educación. Jamás se dará á luz Disertación alguna (por muy bien escrita que este) si es difusa, sino se contrae directamente a objeto americano, ó si contiene alguna expresión ofensiva de las sagradas leyes de la urbanidad"22.

De igual forma, el 27 de enero de 1807 apareció El Alternativo del Redactor Americano, como un suplemento mensual del Redactor consagrado a la publicación de artículos instructivos, escritos filosóficos y poesías del director y que circuló hasta el 27 de noviembre de 1809, con 47 ediciones. Un ejemplo de su objetivo es la nota aclaratoria de la edición XX de agosto de 1808, en la que se advierte sobre la imparcialidad del periódico frente a sus publicaciones, a propósito de una "noticia" de 1807 sobre el estado de los gobiernos en Europa: "Como un papel destinado á comunicar los sucesos corrientes, debe ceñirse siempre a la pública voz y fama, porque de lo contrario se haría ridiculo y sospechoso, y mucho más cuando median circunstancias de alta consideración; de aqui es que los que se tienen por prudentes deben formar sus juicios con equidad. Prevenimos esto, para que se entienda que el Redactor sabe muy bien cuál es la política que debe observar en la publicación de toda especie de noticias; porque su objeto no es de hacer la glosa ni censura critica de los acontecimientos y acciones, sino seguir la opinión común como los demás" 23 .

La intención de Manuel del Socorro era permanecer en fiel a la Corona hasta que los sucesos de la independencia obligaron su giro. Sin embargo, cabe resaltar que en

${ }^{21}$ Otero, Gustavo, Don Manuel del Socorro Rodríguez, cit. (n. 8), p. 20.

${ }^{22}$ Rodríguez, Manuel del Socorro, El Redactor Americano, № 1, de 6 diciembre de 1806, pp. 2-3.

${ }^{23}$ RodrígueZ, Manuel del Socorro, El Alternativo del Redactor Americano, $\mathrm{N}^{\circ} 20$, de 27 agosto de 1808 , p. 158. 
su nueva expresión como americanista político y nuevo revolucionario, sus intentos por formar un nuevo periódico no gozarían la misma suerte que los anteriores. El 17 de agosto de 1810 aparece el primer y único ejemplar de La Constitución Feliz, periódico político y económico de la capital del Nuevo Reyno de Granada, como respuesta del bibliotecario a su necesidad de documentar los sucesos que dieron origen a la revuelta del 20 de julio, y en los que expresa tímidamente su nueva postura patriótica: "En el año de 1810, en que se operó la gran transformación política de nuestra Independencia, el ingenuo bibliotecario, aunque realista de corazón, no se creyó autorizado para manifestar sentimientos contrarios a los profesados por los habitantes de la patria adoptiva, y acogió con relativo entusiasmo las ideas emancipadoras. [...]. Desde luego aquella literatura no era la más apropiada para despertar el entusiasmo patriótico en las muchedumbres, y comprendiéndolo así, la Junta, suspendió la publicación de Rodríguez y encomendó a Caldas y Camacho la del Diario Político, que apareció diez días después" ${ }^{24}$.

Vale anotar, que ya antes de la Constitución Feliz, el bibliotecario había hecho nuevos intentos de publicaciones seriadas para mantener el contacto con los lectores, luego del cierre del Redactor Americano y su suplemento el Alternativo. Sin embargo, estos informativos fueron menores en sus fines y vigencia, aunque tenían la misión de presentar los últimos sucesos ocurridos en Europa: "Al mismo Rodríguez le corresponde la publicación de otras hojas informativas de Bogotá, como el Extracto de las Ultimas Noticias de Europa, y Resumen General de las Ultimas Noticias de Europa, aparecidas en 1807; Ultimas noticias, cuyo primer número vio la luz el 24 de septiembre de 1809 y que a partir de ese tercer número se intituló Los crepúsculos de España y Europa"25.

Sin embargo, para algunos autores la obra de Manuel del Socorro en favor de los intereses revolucionarios de los neogranadinos se cumple en buena parte de su esfuerzo periodístico. Para el cubano Miguel Bonera, tanto el Redactor como el Alternativo del Redactor dieron a conocer a toda una generación de criollos los temas más significativos de la cultura, la ciencia y la administración de las colonias en el nuevo mundo, temas de política americana como las rebeliones negras del Caribe y las Antillas, la expedición libertadora de Miranda en Venezuela y sobre todo las discusiones que sobrevinieron a las obras de George Louis Leclerc conocido como el conde de Buffon y del abate holandés Cornelio de Paw, y otros naturalistas europeos como Raynal y Robertson sobre la inferioridad de los nativos americanos, teorías que fueron rebatidas por Rodríguez y que fueron esenciales para la formación de un pensamiento americanista. "Por otra parte, el Papel Periódico, como el Redactory el Alternativo, informaron de sucesos culturales de importancia universal: el desarrollo de las revoluciones francesa y norteamericana, las primeras discusiones registradas en Inglaterra para abolir la trata negrera, y las acciones de Napoleón en Europa y particularmente en España. Algunos temas eran verdaderos "tabúes"; sin embargo, Rodríguez tuvo la astucia suficiente para burlar la estricta censura y para que tales asuntos no aparecieran como peligrosos a los intereses

\footnotetext{
${ }^{24}$ Otero, Gustavo, Don Manuel del Socorro Rodríguez, cit. (n. 8), p. 24.

${ }^{25}$ Torre, José, Ensayo, cit. (n. 3), p. 19.
} 
de la Corona. Muchas veces llegó a presentarlos en detalle y en la medida de las circunstancias, de la forma más completa, contribuyendo así a formar la opinión pública neogranadina en un clima proamericanista y prerrevolucionario" 26 .

\section{La Tertulia Eutrapélica.}

Dentro de las actividades culturales que Manuel del Socorro realizaba en la biblioteca se destaca la Tertulia Eutrapélica que nace como consecuencia de sus inquietudes intelectuales, y de su interés por socializar con algunos amigos y extraños capitalinos, temas de orden literario, sin embargo, en ocasiones se abordaron temas políticos, económicos, sociales y jurídicos que afectaban de manera evidente al país, o que eran de interés colectivo, pero sobre todo con el objetivo de promover los valores ilustrados de los ciudadanos. De acuerdo con la versión que el mismo Manuel del Socorro dejó registrada en unos de los ejemplares del Papel Periódico el propósito y fin de la Tertulia Eutrapélica era amplio: "Habiéndose formado, en cierta Casa una junta de varios sujetos instruidos, de ambos Sexos, bajo el amistoso pacto de concurrir todas las noches a pasar tres horas de honesto entretenimiento discurriendo sobre todo género de materias útiles y agradables; daremos pues exacta noticia de-esta Asamblea del Buen Gusto, é igualmente iremos publicando (según la oportunidad de hubiere) algunos de aquellos rasgos prosaicos y poéticos más proporcionados para llenar el fin de cada Numero [...]"27.

La Tertulia debía proveer al Papel Periódico buena parte de la producción literaria de sus participantes, que se publicaría con relativa frecuencia en la parte de final de cada número del periódico. Sin embargo, por el perfil biográfico de Manuel del Socorro y de acuerdo a documentos de la época que recrean el ambiente y los temas de la Tertulia Eutrapélica, es posible sobredimensionar el papel que pudo haber jugado como vehículo de formación política libertaria.

Sin lugar a dudas la Tertulia contribuía con un ambiente cultural ilustrado, que hacía más énfasis en el buen gusto literario y estético que en la fundamentación político-jurídica neogranadina. Los textos que se publicaron en el Papel Periódi$c o$, fruto de las ambiciones literarias de sus participantes, permiten relevar dicho perfil. Sería necesario un estudio mucho más detenido para revisar la posibilidad de un contraflujo discursivo con pretensiones revolucionarias que pudo haberse enmascarado detrás del público reporte que se hacía de las tertulias.

\section{Regalismo vs. americanismo.}

La devoción por los monarcas españoles era una condición de vida para sus vasallos de ultramar. En efecto, la temprana fidelidad de Manuel del Socorro con los reyes y con sus representantes en el nuevo mundo, es una constante de su epistolario personal y su proceso creativo. La posición regalista o realista de Manuel del Socorro Rodríguez, se da tanto en los artículos publicados en los

${ }^{26}$ Bonera, Miguel Ángel, Manuel del Socorro Rodríguez. Bibliotecario de las Américas. en Anales de Investigació 1 (2005), pp. 13-22 [visible en: http://biblos.uamerica.edu.co/cgi-bin/ koha/opac-detail.pl?biblionumber=60966, visitado en junio de 2014].

${ }^{27}$ Rodríguez, Manuel del Socorro, Papel Periódico de Santa Fe, Nº 84, de 21 de septiembre de 1792 , p.247 
periódicos ya citados, como en las cartas enviadas al rey español y en algunos de sus sonetos y poemas, pues alababa al rey, en ellas le prometía fidelidad y lealtad, satisfaciendo entonces el deseo español de extender su autoridad mediante el control de quienes eran los gobernados. Su regalismo era normal condición en un hombre de su tiempo: "A mediados el siglo XVIII, el ideario regalista genera una presión semántica y otra léxica. La primera redefine la relación entre el rey y vasallos de tal modo que, de ser entendido como un pacto entre partes con derechos y obligaciones mutuas, y por medio del cual el pueblo cede su soberanía al rey para que lo ejerza en procura del bien común y la felicidad del reino, se entiende ahora que la soberanía del rey está constituida previa e independientemente de cualquier pacto o cesión de los vasallos. Por tanto, ninguna de sus acciones, incluso aquellas tachadas de tiránicas, pueden ser cuestionadas o usadas para impugnar al rey o a sus funcionarios" 28 .

Don Manuel del Socorro se enfrentaba al rigor de ser un modelo de "vasallo fiel" y al hecho de ser un "vasallo ilustrado" que debía además hacer parte del aparato reproductor de los valores regalistas a través de sus periódicos y tertulias. Su misión como súbdito ejemplar consistía en recrudecer el tono de los tratadistas del regalismo de cara a los movimientos de independencia que se empezaron a gestar desde 1781 en la Nueva Granada, y en otras colonias de ultramar, sumado al hecho de la crisis que vivía España para esa época: "En este contexto, los tratadistas del regalismo -tales como Campomanes y Jovellanos- y sus publicistas -como Joaquín Lorenzo- señalan que el ciudadano posee derechos sociales pasivos (i. e., derecho a la seguridad, a la felicidad, etc.), es decir, el ciudadano no está definido por el ejercicio de sus derechos políticos -ni tan siquiera como se entendía en el antiguo régimen-, aquellos que le corresponden con las distinciones que reconocen su calidad. El súbdito del regalismo es exclusivamente sujeto de obligaciones y deberes" ${ }^{29}$.

Sin duda, además de sus compromisos con el ideario regalista, estaba su fidelidad y la amistad con el virrey Ezpeleta, y por supuesto el temor al cambio de sistema, por la natural resistencia ante lo desconocido y lo que pudiera sobrevenir con la ruptura de los ideales monárquicos que tanto había defendido.

Sobre el sentimiento regalista de Manuel del Socorro uno de los textos en los que se señala con fuerza el pensamiento contrarevolucionario de bibliotecario, es la obra de Rafael Antolínez Camargo, en la que a partir de los fragmentos de su obra literaria el autor deja ver la distancia de Rodríguez frente a los movimientos insurgentes del Nuevo Reino. "El Papel Periódico fue, sin duda, un difusor del sentimiento regalista. Su editor, Don Manuel del Socorro Rodríguez fue un fiel vasallo de la corona española y un preclaro defensor del sistema monárquico mientras las circunstancias (independencia de la Nueva Granada), así lo permitieron y así lo expresaba en su hebdomadario: "El amor que debemos tributar á nuestros soberanos: el interés que debemos tener en sus regocijos y la preferencia que debemos dar aún a los más pequeños sucesos de nuestro natural Señor, no

\footnotetext{
${ }^{28}$ OrTeGa, Francisco, Sacrificar la Reputación de literato al título de ciudadano: Buen Gusto y cultura política neogranadina a finales del siglo XVIII. en Cuadernos Dieciochistas, 14 (2013), p. 83.

${ }^{29}$ Ibíd.
} 
es una costumbre dimanada solamente del voluntario consentimiento de los Pueblos; es una obligación deducida del mismo centro de la Religión Christiana" (Rodríguez, I, 15, 113-114)"30.

En una relación de varios textos poéticos entre ellos sonetos, madrigales, elegías o en la prosa la admiración o dolor Manuel del Socorro deja ver su devoción por los monarcas, los sucesos que enmarcaban sus vidas como cortesanos, se convirtieron en el motivo central de sus creaciones: "[...] siguiendo la línea de aceptación y sumisión a la monarquía, de raíces teocráticas la poesía de Manuel del Socorro atacó y ridiculizó el movimiento revolucionario francés con el cual se depuso, en aquella nación, la monarquía; en este sentido, dio a la luz pública un poema en prosa á la muerte de la Reyna de Francia, titulado 'El imperio de la virtud', que abarcó desde el ejemplar número 216, del 30 de octubre de 1795, hasta el 236, de marzo 18 de 1796. Este poema en prosa narraba la muerte de María Antonieta de Lorena, reina de Francia e hija del rey Francisco I y de María Teresa de Austria, a manos de los revolucionarios franceses que la llevaron a la guillotina, luego de su cautiverio en el Temple" 31 .

El sentimiento excesivo de amor por la corona se fractura cuando Manuel del Socorro se muestra en contra de España para que no siguiera interviniendo directamente en las decisiones de los americanos en vísperas y luego de la independencia. El nuevo Manuel del Socorro se muestra con amplitud en La Constitución Feliz, Periódico político y económico de la Capital del Nuevo Reyno de Granada, editado el 17 de agosto de 1810, en donde expresa el ideario independista neogranadino que triunfa con la revuelta del 20 de julio de 1810 , aunque con el tono moderado que señala como la causa del nuevo estado de las cosas a la voluntad divina: "Si los Gobiernos establecidos por el horrendo título de conquista son respetados y obedecidos de los hombres; ¿cuánto mas deberán serlo aquellos que establecen la razón y la sabiduría, para desagraviar la Divina Religión, asegurar la legitima soberanía, abolir el despotismo, honrar la humanidad, y perpetuar el bien común? Tales son por cierto o timbres y blasones que adornan el nuevo solio erigido a la justicia en la M.N. y M.L. Ciudad de Santa Fe de Bogotá, Capital del Nuevo Reino de Granada. No ha sido esta una obra del capricho humano sino del poder Divino [...]"32.

No fue fácil para el bibliotecario asumir el nuevo tono y ello se refleja en un texto tímido en sus planteamientos, y advirtiendo una pretensión de imparcial testigo de los nuevos hechos. A pesar de ser una pieza excepcional en plena luz de los sucesos del 20 de julio de 1810, este escrito no tuvo mayor poder de convencimiento, porque luego de su publicación hubo otros textos más frontales como aquellos del Diario Político realizados por solicitud de Nariño a Caldas y Camacho ${ }^{33}$.

\footnotetext{
${ }^{30}$ Antolínez, Rafael, El papel periódico de la Ciudad de Santa Fe de Bogotá: Vehículo de las luces y la Contrarrevolución (Bogotá, Banco Popular, 1991), p. 106.

${ }^{31}$ Ibíd., p. 108.

${ }^{32}$ Rodríguez, Manuel del Socorro, La Constitución Feliz, Periódico político y económico de la Capital del Nuevo Reyno de Granada, N 1, de 17 de agosto de 1810, p. 1.

${ }^{33}$ Padilla, Iván Vicente. Sociedad y cultura en la obra de Manuel del Socorro Rodríguez de la victoria (Bogotá, Editorial UN, 2012).
} 
Con la Constitución Feliz el bibliotecario, en tono moderado, sentó el precedente de su compromiso e interés por las ideas de su pueblo, el sentimiento de patriotismo y el amor por los naturales del Nuevo Reino debía imperar sobre su natural predilección por la Corona: "Proclamada la revolución de 1810, el bondadoso Rodríguez, que era realista por la humilde y simpática sencillez de su corazón, y que había llenado su periódico de poesías en honor a los reyes de España; todavía, decimos, dio a la luz otros periódicos, entre ellos la Constitución Feliz, de los que no pudieron salir sino muy pocos números, porque su modesto y mediano pero laborioso ingenio se eclipsaba ante los robustos talentos de caldas, Zea, Nariño, los tres Gutiérrez (José María, Fruto, y José Gregorio). Acebedo, Padilla, Pombo, Valenzuela y otros tantos hijos de 1810"34.

Sin duda Manuel del Socorro viejo y disminuido, enfrentado al nuevo estado de cosas de los naturales del virreinato y de todas las colonias, debe abdicar de su devoción regalista y tornar por la senda del americanismo, que hasta entonces había sido defendido en sus obras como el triunfo de las riquezas propias del nuevo mundo, mas no de su independencia política de España. Desde su llegada a Santa Fe se había declarado hijo de esta tierra y había trabajado incansablemente para procurar desde su limitada visión, el avance de los neogranadinos. Como lo documenta José María Vergara y Vergara en un perfil del bibliotecario: "Hemos dicho que era ferviente realista: Bogotá proclamó la independencia y luego la república, y Rodríguez se hizo republicano, porque no creyó que le era permitido sostener opiniones contrarias a las de su cara patria adoptiva. Pero Rodríguez, corriendo tras la revolución bogotana, con su mediano ingenio y su alma apacible, era como un perro anciano, cuyo dueño se va al extranjero y que se lanza sin consultar sus fuerzas sino su leal afecto, tras la brillante y rápida carroza que lleva a su amo, quedando muerto de cansancio en el camino sin haber alcanzado a volver a ver la faz querida del amo que lo deja" ${ }^{35}$.

Sin embargo, sus méritos como bibliotecario reflejan su profundo amor por el conocimiento y su deseo de compartirlo con los jóvenes santafereños, como parte del profundo sentimiento americanista que se expandió desde la Real Biblioteca y como testimonio del final de su vida consagrado a la causa de los naturales del nuevo reino: "Como bibliotecario, es indeclinable el servicio que nos hizo: además de mantener con el nimio aseo los volúmenes fiados a su honrada custodia, enriqueció el establecimiento con varios manuscritos curiosos, y con todas las producciones de la imprenta americana, que recopilaba cuidadosamente y depositaba empastados en la biblioteca. Se le remitieron, como a redactor del Papel Periódico varias memorias científicas sobre el coto, la viruela, y otras enfermedades que adornan a la humanidad en estas regiones, y como por la extensión de los manuscritos, no pudo insertarlos, los encuadernó y depositó en la biblioteca, haciendo otro tanto con todos los materiales de alguna importancia que le venían a las manos, o mejor dicho a la caja, pues mantenía constantemente una caja cerrada y con buzón, en

\footnotetext{
${ }^{34}$ Vergara, José, Historia de la literatura en la Nueva Granada. Desde la Conquista hasta la independencia (1538-1820) (Bogotá, Librería Americana, 1905), p. 11.

${ }^{35}$ Ibíd., p. 11.
} 
el correo, para que en ella echasen sus manuscritos los autores, que tuvieran pena, vergüenza o cualquier impedimento en dar su nombre" 36 .

Independientemente de las ideas regalistas que haya expresado Manuel del Socorro, algunas anécdotas lo señalan insurgente. Las notas del biógrafo Gustavo Otero Muñoz, en la edición de la Historia de la literatura de Nueva Granada relatan el memorable esfuerzo quijotesco del anciano bibliotecario por mostrarse complemente adherido con la causa de la independencia, dejando de lado su fervor monárquico, relacionado con un duelo en que él ofreció su vida para enfrentarse contra Antonio Baraya: "El 9 de enero de 1813 las tropas federales venían hacia Santa Fe, acaudilladas por Don Antonio Baraya, y dispuestas a hacer entrar en razón al gobierno centralista de Nariño. "Cuando acampaba Baraya frente a la ciudad, y en esta se prevenían para la batalla, don [sic] Manuel del Socorro Rodríguez elevó al gobierno un memorial en que manifestaba que amando con todo su corazón esta patria adoptiva para él, le dolía ver que iba a correr la sangre de sus hijos en una batalla fratricida; que para que este sacrificio se ahorrara, se ofrecía él como campeón de Santa Fe para lidiar cuerpo a cuerpo con Baraya"37.

Sin embargo, su contradictoria figura de insurgente contrasta con la anécdota que en 1816 salvaría su vida de la arremetida por la reconquista que emprendería Pablo Morillo: El pacificador Morillo ordenó que fuera arrestado en su pieza de habitación, situada en el mismo local de la Biblioteca, sin permitir siquiera que le entraran el más ligero alimento. Después de dos días de encierro y ayuno forzosos, el jefe español se presentó en persona a interrogar al inofensivo hombre de letras acerca de su participación en el movimiento revolucionario. Afortunadamente para nuestro biografiado, el retrato de Fernando VII se hallaba colocado en sitio bastante visible del salón, desde el año de 1809, y al verlo, don Pablo Morillo aplacó como por ensalmo todas sus cóleras, ordenando al punto la libertad del aterrado anciano ${ }^{38}$.

Luego del famoso incidente con Morillo, el americanista, "revolucionario" y anciano bibliotecario, muere en la pobreza y la soledad que lo acompañaron la mayor parte de su vida. Asistió al cambio de régimen político jurídico en el Nuevo Reino, fue consciente que España había perdido su control sobre las colonias de ultramar y que criollos en toda América Latina, estaban dispuesto a entregarlo todo por la instauración de la república, que había triunfado en el viejo mundo como respuesta a la tiranía monárquica.

Finalmente, vale la pena señalar que existe un buen número de textos que reivindican la figura del Manuel del Socorro de cara a una discusión más profunda sobre el alcance y sentido de su obra. En ellos es manifiesta la tensión y la génesis de los valores ilustrados en la sociedad neogranadina ${ }^{39}$ y la hibridación cultural que favorecía el colonialismo entre un pensamiento premoderno colonial y la

\footnotetext{
${ }^{36}$ Ibíd., p. 11-12.

${ }^{37}$ Ibíd., p. 18.

${ }^{38}$ Ibíd., p. 18.

${ }^{39}$ Silva, Renán, Los ilustrados de Nueva Granada 1760-1808: Genealogía de una comunidad de interpretación (Medellín, EAFIT - Banco de la República, 2008).
} 
modernidad republicana ${ }^{40}$ que se inaugura con el triunfo de los valores ilustrados de las revoluciones francesa y norteamericana.

La figura de Manuel del Socorro, como la de otros ilustrados representa esa tensión-hibridación entre esos dos discursos regalistas y americanistas, comprendiendo los matices que nos permiten seguir afirmando que el bibliotecario fue un hombre de su tiempo, que tuvo que articular la manera como España reconfigura los discursos ilustrados para acomodarlos a su proyecto político de dominio colonial ${ }^{41}$.

El propósito de ilustración de las reformas borbónicas estaba lejos de pretender la libertad de sus colonias, pretendía, más bien, lograr la cohesión cultural con España, para conjurar su crisis interna como consecuencia de la Invasión Napoleónica y las tensiones con Inglaterra, a través de los discursos de la libertad, el progreso y la felicidad de los pueblos, pero sin desmarcarse de los valores hispánicos apoyados en el fervor religioso, la lealtad monárquica y el conformismo social que imponía la condición de súbdito. Los ilustrados neogranadinos retomaron varias de estas ideas y, a su vez, consideraban que era fundamental promover y consolidar la cohesión cultural con España; el estudio de las ciencias naturales y exactas; la generación de avances científicos y técnicos; la producción de conocimiento propio; el reordenamiento de la ciudad, entre otros. No obstante, en un sentido más profundo, a través de estas ideas ilustradas se buscaba llevar a cabo la reconquista espiritual a favor de un cambio de mentalidad, los valores y prácticas de los individuos con el objetivo de afianzar las relaciones de dominio colonial ${ }^{42}$.

Un retrato de esa tensión entre americanista y regalista, lo presenta en término de las ambivalencias propias de quien tiene que defender su identidad como nativo del nuevo mundo y heredero del pasado prehispánico, pero un hombre culto, un "vasallo ilustrado" que debe su cultura a los valores civilizados de la madre patria. "Se trata, evidentemente, de un americanismo definido en torno a ciertas ambivalencias: a un mismo tiempo el ilustrado de origen cubano trató de recuperar los valores culturales prehispánicos, a través de su reivindicación y su estudio histórico, mientras defendía algunos elementos del poder colonizador español, tales como la monarquía y la razón cristiana, en el marco de un pensamiento ilustrado moderado" 43 .

En efecto un aspecto culminante de su consideración como "americanista" aunque sea de tono moderado, la expresa Castro Henao cuando afirma que Manuel del Socorro no defendió con vehemencia la causa de la independencia, no por falta de comprensión de la realidad que se avizoraba sino, porque consideraba que no se podía ser americano renunciando a la riqueza de cultura hispánica: "Rodríguez

\footnotetext{
${ }^{40}$ CASTRO-Gómez, Santiago, La "hibrys" del punto cero: ciencia, raza e ilustración en la Nueva Granada (Bogotá, Universidad Javeriana - CEJA, 2005).

${ }^{41}$ Moreno, Liz, La cuestión moderno-colonial en el Papel Periódico (1791-1796): Las prácticas ilustradas de Manuel del Socorro Rodriguez en Lingüistica y Literatura, 61 (2011), p. 181.

${ }^{42}$ Ibíd., p. 182.

${ }^{43}$ CASTRO, Pablo, Pensamiento americanista en la Nueva Granada: la conciencia histórica en la obra periodística de Manuel del Socorro Rodríguez de la Victoria (1791-1810), en Lingüistica y Literatura, 61 (2012), p. 153.
} 
no podía promover la idea de independencia, pues consideraba que parte de la definición de América dependía de los valores españoles, pero esta circunstancia no le impidió comprender el advenimiento de unos procesos históricos en los cuales América fue ganando autonomía cultural que sería reivindicada en diversos grados por quienes adelantaron el proceso para consolidar la autonomía cultural" ${ }^{44}$.

Manuel del Socorro vivió y padeció esta tensión contribuyendo con unos propósitos que estaban por encima de su capacidad para poder desenmascararlo. Apenas tuvo tiempo de legarnos un repertorio de voces, textos y discursos, en una pretensión de objetividad, a partir de las cuales se pueda hoy recuperar y leer entrelíneas la transición del sistema.

\section{CONCLUSIONES}

La figura de Manuel del Socorro Rodríguez es arquetípica como hombre de su tiempo, supo acomodarse, no sin padecimientos, a las lógicas del sistema imperante, y vivir en la ambivalencia y el enmascaramiento que fueron tan propios de la cultura hispanoamericana con el contacto de los dos mundos. Vivió como regalista acendrado y como americanista convertido, pero sin lugar a duda su rol como defensor de los textos y discursos, bien en defensa de España o de los naturales americanos, es uno de los más grandes aportes que este ilustrado le hizo al proceso de formación de las naciones latinoamericanas.

Sin embargo, la experiencia de Manuel del Socorro y la de otros ilustrados del nuevo mundo obliga a realizar un estudio más detenido sobre la confrontación de los valores regalistas y americanistas en periodo de transición Colonia-República en la Nueva Granada, de cara a un análisis de las circunstancias expresadas en los textos y discursos de la época, que permitan reconstruir la formación de los sujetos y de las instituciones político-jurídicas del país, y de las otras naciones latinoamericanas que vivieron el mismo tránsito.

La ambivalencia producto de la contraposición discursiva entre regalismo vs. americanismo se va a reflejar en la determinación de los criollos neogranadinos en su expresión como ciudadanos y en la responsabilidad de organizar las instituciones sociales, económicas y jurídicas de la naciente república sin haber asimilado los cambios y con el peso de una tradición cultural que en la mayoría de sus expresiones textuales y discursivas (lengua, religiosidad, hábitos cotidianos, etc.) estaba intimamente ligada a la madre patria y a su proyecto de control colonial.

Finalmente, vale destacar que el tránsito personal de Manuel Socorro, es representativo del tránsito colectivo que experimentaba la sociedad neogranadina, y las naciones hispanoamericanas en procesos de independencia frente al dominio monárquico español. La Real Biblioteca de Santa Fe una oportunidad de primer orden para estar en contacto con las corrientes de pensamiento revolucionario francés y norteamericano, con el ideario científico (y más adelante político) de la Ilustración y con la consolidación de un pensamiento sobre lo propio, aunque nutrido de la tradición europea.

\footnotetext{
${ }^{44}$ Ibíd., pp. 167-168.
} 
La labor de custodia de los textos y discursos contenidos en los libros de la Real Biblioteca, constituye un escenario propicio para la formación cultural de los neogranadinos, ello sumado a la tertulia y a los diarios que creó y puso en circulación Manuel del Socorro, permitieron un ambiente de lectura y reflexión, como podría observarse en una revisión más detenida de los contenidos de cada una de las entregas, y sin lugar a dudas dichos contenidos en sus variadas expresiones, encontraron un germen importante para una cultura política y jurídica entre los lectores y contertulios neogranadinos.

\section{BiBLIOGRAFÍA}

Fuentes primarias

Rodríguez, Manuel del Socorro. Papel periódico de santa fe de Bogotá. Banco de la Republica. [visible en internet: http://www.banrepcultural.org/blaavirtual/historia/papel-periodico-de-santa-fe-de-bogota/v2/Papel\%20periodico no84 baja. pdf.] (1792),

El redactor americano. [visible en internet: http://www.banrepcultural. org/blaavirtual/hemeroteca-digital-historica/el-redactor-americano-periodico-delnuevo-reyno-de-granada], (1806)

. El alternativo del redactor americano. [visible en internet: http:// www.banrepcultural.org/blaavirtual/hemeroteca-digital-historica/el-alternativodel-redactor-americano, $]$ (1808)

La constitución feliz. [visible en internet: http://www.banrepcultural. org/sites/default/files/lablaa/historia/constitu-feliz/1.pdf,] (1810)

Vergara, Jose María. Historia de la literatura en la Nueva Granada. Desde la Conquista hasta la independencia (1538-1820). (Bogotá: Librería Americana, 1905) 7-21

Fuentes secundarias

Antolinez C., Rafael. El papel periódico de la Ciudad de Santa Fe de Bogotá: Vehículo de las luces y la Contrarrevolución. (Bogotá, Banco Popular, 1991).

Bonera M., Miguel Ángel. Manuel del Socorro Rodríguez. Bibliotecario de las Américas. Biblioteca Anales de Investigación, ( 2005), pp.113-122.

Castro-Gómez, Santiago. La hibrys del punto cero: ciencia, raza e ilustración en la Nueva Granada (1750-1816).(Bogotá, Ceja- Universidad Javeriana, 2005).

Cacua P., Antonio. (Ed.). Don Manuel del Socorro Rodríguez - Itinerario documentado de su vida, actuaciones y escritos. Fundador del Periodismo colombiano. (Bogotá, ICELAC, 1985).

Castro H., Pablo. Pensamiento Americanista en la Nueva Granada: la conciencia histórica en la obra periodística de Manuel del Socorro Rodríguez de la Victoria (1791-1810) Lingüistica y Literatura, no.61, pág. 151-171 (Bogotá, Universidad Nacional de Colombia, 2012)

ForTich, Mónica. Togados y letrados, libros, lecturas y bibliotecas en la formación de los abogados neogranadinos 1739-177. (Bogotá, Editorial Universidad Libre, 2011)

Garavito, Julián. Un Vinculo Cultural entre Cuba y Colombia: Manuel del Socorro Rodríguez. [Visible en internet: http://mdc.ulpgc.es/cdm/ref/collection/tebeto/ id/147.] (N.D) 
Hernández de A., Guillermo y Carrasquilla B., Juan. Historia de la Biblioteca Nacional de Colombia. (Bogota, Publicaciones Instituto Caro y Cuervo, 1997).

Moreno, Liz. La cuestión moderno-colonial en el Papel Periódico (1791-1796): Las prácticas ilustradas de Manuel del Socorro Rodríguez. en Lingüistica y Literatura, no.61, pp. 173-190 (Bogotá, Universidad Nacional de Colombia, 2011).

ORTEGA, Francisco. Sacrificar la reputación de literato al título de ciudadano: Buen Gusto y cultura política neogranadina a finales del siglo XVIII en Cuadernos Dieciochistas, No. 14, pp. 77-96 (Ediciones Universidad de Salamanca, 2013) 77-96.

Otero Muñoz, Gustavo. (Ed.). Don Manuel del Socorro Rodríguez: homenaje en el II centenario de su nacimiento. (Bogotá, Editor Biblioteca del Banco de la República, 1938).

Padilla C., Iván Vicente. Sociedad y cultura en la obra de Manuel del Socorro Rodríguez de la Victoria. Primera edición. (Bogotá, Editorial Universidad Nacional de Colombia, 2012).

Sedeño G., Kevin. La "apología de los ingenios Neogranadinos" y la constitución del canon de la literatura colombiana: Manuel del Socorro Rodríguez (1758-1819). (Bogotá, Universidad Nacional de Colombia, Fundación Universitaria del Área Andina, 2011).

Silva, Renán. Los ilustrados de Nueva Granada. 1760-1808: Genealogía de una comunidad de interpretación (Medellín, EAFIT, Banco de la República, 2008).

TORRe ReVEllo, José. Ensayo de una biografía del bibliotecario y periodista Don Manuel del Socorro Rodriguez, en Revista Thesaurus, Instituto Caro y Cuervo. [Visible en internet: http://cvc.cervantes.es/lengua/thesaurus/pdf/03/TH $03 \quad 1230070$. pdf.] (1974). 
